\title{
ENSINO E APRENDIZAGEM EM GEOGRAFIA E OS MOTIVOS DOS ALUNOS: A APOSTA DO/NO LUGAR
}

\author{
ENSEÑANZA Y APRENDIZAJE DE LA GEOGRAFÍA Y LOS MOTIVOS DE LOS \\ ALUMNOS: LA APUESTA DEL/EN EL LUGAR
}

\section{TEACHING AND LEARNING IN GEOGRAPHY AND THE STUDENTS’ MOTIVES: THE BET OF/ON THE PLACE}

\author{
Izabella Peracini Bento - Universidade Federal de Goiás - Goiânia - Goiás - Brasil \\ izabellaperacini@yahoo.com.br
}

\begin{abstract}
Resumo
Este artigo tem por objetivo promover uma discussão acerca dos motivos dos alunos, com base em "seu lugar", enquanto uma "aposta" para potencializar o processo de ensino e aprendizagem em Geografia. Com isso, tornase pertinente analisar como o professor, a Geografia e a educação podem contribuir com a formação de cidadãos conscientes e críticos, capazes de transitar entre os conceitos e as abordagens geográficas que representam as transformações contemporâneas. A categoria lugar vem se constituindo em uma rica ferramenta para 0 ensino de Geografia, pois está claro que a realidade local relaciona-se com o contexto global, e isso deve ser trabalhado de forma abrangente durante toda a escolaridade. 0 interesse em trabalhar o lugar como mediação didática no processo de ensino e aprendizagem em Geografia emerge do entendimento de que é possível, a partir do estudo dessa categoria de análise, dimensionar a concretude do mundo no lugar, encontrar os elementos globais no lugar. Estabelecer as relações do próximo com 0 distante pode levar 0 aluno a elaborar novas questões sobre 0 ser e 0 estar no mundo.
\end{abstract}

Palavras-chave: ensino-aprendizagem em Geografia, motivação, motivos, lugar.

\begin{abstract}
This article has the objective to promote a discussion about the student's motives, from "their place", as a "bet" to potentiate the teaching and learning process in Geography. With that, it becomes pertinent to analyze how the teacher, Geography and education can contribute with the formation of conscientious and critical citizens, which are capable of transiting amongst the concepts and geographical approaches that represent the contemporary transformations. To that end, it is worth mentioning that the category place has been constituting itself in a rich tool for the teaching of Geography, because it is obvious that the local reality relates itself with the global context, and that should be addressed in an encompassing way during the entirety of schooling.The interest in addressing the place as didactic mediation in the teaching and learning process in Geography emerges from the understanding that it is possible, from the study of that category of analysis, to dimension the concreteness of the world on the place, to find the global elements on the place. To establish the relationships of the near with the distant can lead the student to elaborate new questions about being and standing in the world.

Key words: teaching-learning in Geography, motivation, motives, place.
\end{abstract}

\section{Resumen}

Este artículo tiene como objetivo promover una discusión acerca de los motivos de los alumnos, a partir de "su lugar", en cuanto una "apuesta" para potencializar el proceso de enseñanza y aprendizaje en Geografía. Con eso, se torna pertinente analizar como el profesor, la Geografía y la educación pueden contribuir con la formación de ciudadanos conscientes y críticos que sean capaces de transitar entre los conceptos y abordajes geográficos que representan las transformaciones contemporáneas. Para eso, vale destacar que la categoría lugar se viene constituyendo en una rica herramienta para la enseñanza de la Geografía, pues está claro que la realidad local 
se relaciona con el contexto global, y eso debe ser trabajado de forma importante durante toda la escolaridad. El interés en trabajar el lugar como mediación didáctica en el proceso de enseñanza y aprendizaje en Geografía emerge del entendimiento de que es posible, a partir del estudio de esta categoría de análisis, dimensionar la concritud del mundo en el lugar, en que es posible encontrar los elementos globales en el lugar. Establecer las relaciones de lo próximo con lo distante puede llevar al alumno a elaborar preguntas sobre el ser y estar en el mundo.

Palabras clave: enseñanza-aprendizaje en Geografía, motivación, motivos, lugar.

\section{Introdução}

Os professores, em geral, precisam administrar melhor a ideia de que sua prática profissional lhes exige dois pré-requisitos: por um lado, o de ter domínio do conteúdo a ser ensinado por eles e, por outro, o de ter domínio dos elementos pedagógico-didáticos, além de outros saberes relevantes, para que, de fato, eles possam encaminhar seu trabalho de modo que os alunos aprendam o que eles querem lhes ensinar. Nesse sentido, Libâneo (2009, p. 80) ressalta que, para assegurar a aprendizagem dos alunos, não lhes basta dominar os conhecimentos específicos e transmitir a matéria, "eles precisam dominar procedimentos de ensino que, no mínimo, impliquem o planejamento do ensino, as formas de mobilizar o interesse e a motivação do aluno, a organização da classe, um conhecimento da vida do aluno”. É necessário, assim, compreender os desejos e as necessidades que o aluno traz para a escola, sabendo que cada um se insere no ambiente escolar por motivos e necessidades distintos; por isso, a importância de se inserirem na prática aspectos de orientação psicológica, para entender melhor como funciona a mente do aluno, como se dá o desenvolvimento do comportamento humano.

Nessa linha de raciocínio, emerge a preocupação em compreender elementos da motivação, uma vez que se busca saber como o lugar, enquanto categoria de análise, pode contribuir com uma mediação didática peculiar e desejável para o processo de ensino e aprendizagem em Geografia. Assim, uma questão norteia esse entendimento: é possível que a categoria lugar delimite um caminho para se intervir nos motivos dos alunos e, assim, contribua com uma mediação didática desejável no processo de ensino e aprendizagem em Geografia? Alguns autores dão essencial importância à consideração dos motivos dos alunos para a compreensão do processo de ensino. É nesse sentido que as contribuições de Libâneo (2009, 2011), Souza (2008) e Mouly (1973) são relevantes para trabalhar melhor o conceito de motivação. 


\section{A importância da motivação para ensinar e aprender Geografia}

Souza (2008, p. 65) destaca bem a importância de estudar, de entender melhor o conceito de motivação no processo de ensino, quando afirma que este conceito, no âmbito escolar, está diretamente ligado à mobilização com as atividades, a partir das quais é perceptível um maior envolvimento dos alunos, especialmente, no que se refere à atenção, concentração e reflexão sobre o tema estudado. E ressalta que, para assumir a responsabilidade de motivar seus alunos, o professor precisa partir do conhecimento prévio que eles trazem para a sala de aula, precisa considerar seus interesses, ritmos, a forma com que aprendem, o significado que dão às coisas etc. Enfim, os alunos chegam à escola com uma bagagem repleta de necessidades, objetivos, interesses, conhecimentos, experiências vividas e sentidas no seu dia a dia, o que vai delinear os seus motivos. Acrescente-se que, entre esses motivos, estão aqueles que os impulsionam para estar na escola, pois sabe-se que, muitas vezes, são motivos que não estão ligados à aprendizagem. Como o professor deve proceder nesses casos? Como intervir nos motivos dos alunos para que eles queiram aprender e fazer da sua permanência na escola uma experiência ou oportunidade de construção de conhecimentos?

Nesse sentido, Souza (2008, p. 65) faz uma importante ponderação sobre a motivação dos alunos que estão inseridos nos cursos de formação, os futuros professores. Esse tema não costuma ser uma preocupação na formação inicial desses indivíduos. Consequentemente, quando vão para a escola, os professores tendem a reproduzir sua formação, restringindo-se às ações de educar cognitivamente seus alunos, ignorando seus motivos, o que resulta no não cumprimento do objetivo básico do processo de ensino: a aprendizagem. A autora complementa seu argumento afirmando que "para educar é imprescindível que se tenha um motivo, um projeto, uma ideologia. Nesse caso, o educador ultrapassa o âmbito da ciência, entrando na vontade, âmbito que implica o querer fazer" (2008, p. 65). Assim, não basta apenas a preocupação com os motivos dos alunos, pois o professor também precisa ter um motivo, precisa ir além da ciência, ter projetos, ideologias, precisa ter vontade, querer fazer, querer transformar.

Essa é uma reflexão pertinente, por fazer pensar que além das várias ações que precisam organizar e dirigir, aos professores caberia, ainda, mobilizar seus alunos para que queiram aprender e conhecer. Para isso, 
é preciso provocá-los, caso essa motivação ainda não esteja presente neles. Conforme Souza (2008, p. 66), "planejar para motivar representa um desafio enorme", afinal as ações dos professores, por si só, não são suficientes para intervir nos motivos dos alunos. Os professores não podem obrigar os alunos a aprender ou a valorizar o processo de ensino, acreditando que culturalmente é o correto a se fazer. Eles podem buscar ou criar meios para mobilizar esses alunos para os objetivos que almejam, pois, para aprender, eles precisam querer e se dedicar intelectualmente (Charlot, 2005).

$\mathrm{Na}$ busca por meios de mobilizar os alunos em seus motivos para a aprendizagem, no processo de ensino, não se pode deixar de considerar o conteúdo a ser ensinado, enquanto elemento que constitui o tripé no processo de ensino e aprendizagem, ao lado do professor e do aluno. Como um ponto fundamental a essa discussão, as orientações de Libâneo (2009, 2011) aclaram o que vem se pensando sobre a análise de conteúdo e os motivos dos alunos. Em pesquisa recente, o autor afirma que "duas tarefas essenciais precisam ser assumidas pelo professor ao planejar o ensino para a formação de ações mentais: a análise do conteúdo e os motivos dos alunos" (2011, p. 203). Ele também destaca que o processo de planejamento do ensino se inicia com a análise de conteúdo e que uma boa análise deste favorece a formulação de atividades de aprendizagem que estimulem os motivos dos alunos para o conteúdo.

Segundo o autor, a aprendizagem de conteúdos envolve o desenvolvimento da personalidade se houver ligação entre o conteúdo e os motivos dos alunos para aprender. Esse fato implica a necessidade de se pensar os conteúdos a partir do interesse dos alunos que se quer atingir. Assim, Libâneo (2011, p. 205) conclui que "o modo de organizar o ensino, a forma e o conteúdo das atividades de ensino, são um fator motivacional”; e ressalta que, nessa vinculação entre conteúdos e motivos, não é apenas o ensino que deve estar adequado aos motivos dos alunos, mas também os conteúdos que mobilizam neles motivos por meio de ações com o próprio conteúdo.

Pensar a motivação envolve considerar que este é um dos conceitos fundamentais da psicologia e que tem interesse específico para o professor. Assim, as orientações de Mouly (1973, p. 256) justificam o trabalho dessa temática como um aspecto do comportamento humano estudado pela Psicologia. Segundo o autor, "a motivação envolve uma complexa 
interação das condições do indivíduo e do ambiente total em que se encontra”. Sendo assim, o professor, muitas vezes, não compreende o que interessa à criança, uma vez que o trabalho escolar pode não estar ligado às suas necessidades e intenções. Para o autor, um dos problemas mais importantes do ensino é a motivação e ele defende a necessidade de o professor compreender não somente a teoria, mas também o método de motivação, de maneira que possa potencializar o seu trabalho como docente. Na concepção de Mouly (1973, p. 257),

a criança, na sala de aula, não aprende porque tenha um interesse inato nas dificuldades da Álgebra ou da História; aprende porque, ao fazê-lo, pode satisfazer suas necessidades de reconhecimento social, autoestima, e participação, e porque tais aprendizagens são importantes para seus motivos de hábito e seu autoconceito. De outro lado, muitas crianças não estão motivadas para o trabalho escolar apenas porque a experiência passada lhes mostrou que a escola nada representa para satisfação de suas necessidades.

Entende-se, com isso, que, enquanto os alunos puderem satisfazer suas necessidades de interesse imediato fora da escola, sem os conteúdos veiculados, eles não se interessarão pelo trabalho dentro da escola. Nas aulas, seus esforços serão apenas para evitar os castigos e as punições. Dessa forma, pode-se perceber que o comportamento dos alunos não ocorre de forma espontânea, mas como resposta aos motivos do indivíduo. É pela falta de interesse e motivação que alguns se comportam inadequadamente em sala de aula. Muitas vezes, essa é a raiz da indisciplina.

Mouly (1973, p. 260) afirma que a motivação deve ser um problema de cunho individual, cujo resultado se dá através de necessidades e intenções do próprio indivíduo. Entende-se, assim, que a eficiência da aprendizagem está diretamente relacionada com a motivação do sujeito, seja ela consciente ou inconsciente. O autor afirma ainda que o professor não precisa se preocupar em criar novos motivos no aluno, ele deve se valer daqueles que ele já possui e dirigi-los para a busca de objetivos satisfatórios. Um exemplo disso é quando em sala de aula os alunos têm a possibilidade de experienciar o que aprenderam. Nesse caso, motivá-los não constitui um problema, pois trabalharão com entusiasmo e iniciativa. O problema é que, muitas vezes, a aprendizagem que a criança constrói em sala de aula não tem relação direta com qualquer experiência fora da escola. 
É preciso reconhecer que os alunos nem sempre estão interessados no que a escola tem a oferecer, pois não veem aplicabilidade em sua vida prática, não conseguem ver significado para seus objetivos e intenções imediatos. Para isso, Mouly (1973) considera a importância de o currículo se tornar mais dinâmico, mais ligado às necessidades das crianças, de forma que a escola possa concorrer com as outras atividades que pedem a atenção delas.

A motivação na sala de aula tem se tornado um dos aspectos mais perturbadores do ensino e de difícil resolução, uma vez que a raiz de seu problema pode estar na falta de compreensão do professor em relação ao comportamento humano. O professor, em sua formação, muitas vezes, não é munido de capacidades e habilidades para lidar com aspectos psicológicos e de cunho comportamental. Em sua prática, ao trabalhar com pessoas, acaba tendo que lidar, mesmo que de forma imprudente, com esses elementos da realidade humana. Vale reiterar que a motivação nesse trabalho está diretamente ligada ao lugar como elemento do raciocínio geográfico. Assim, investiga-se como a referência ao lugar vivido e experienciado pelos alunos pode mobilizá-los em suas motivações para compreender e apreender determinado conteúdo.

Pode-se, assim, entender a relação existente entre a motivação dos alunos, seu lugar e a cultura geográfica dos jovens escolares, jovens estes que atribuem significados e relações de pertencimento e de identidade com determinados locais, tecendo em seu cotidiano práticas espaciais propícias para uma abordagem geográfica em sala de aula.

Nesse sentido, corrobora-se o entendimento proposto por Callai (2000) de que um lugar é a reprodução, em um determinado tempo e espaço, do mundo, do todo. "As relações não são pautadas pelo espaço, pela proximidade, pela contiguidade, muito pelo contrário, ultrapassam as distâncias lineares e contínuas, estabelecendo-se a partir de interesses, que são externos na maioria das vezes" (p. 107). Esse entendimento qualifica a afirmação de que a vivência, o espaço experienciado da criança e do jovem, lhes dá compreensão e domínio de lugares que lhes são significativos. Como não utilizar esses saberes construídos pelos jovens nas aulas de Geografia para promover o raciocínio geográfico? O lugar tem assumido posição de destaque nos últimos anos justamente por ganhar significado valioso em uma época que se fala tanto em globalização. Afinal, nos luga- 
res é que o global se concretiza, com conotações específicas e peculiares que lhes permitem ter identidades.

\section{Os motivos dos alunos e a aposta no/do lugar}

Com base na realidade contemporânea em que se está inserido, à qual a Geografia escolar precisa atender, novas concepções referentes à ciência geográfica estão em debate. Torna-se pertinente, no âmbito escolar, a preocupação com o papel do geógrafo, principalmente no que se refere ao desenvolvimento da docência, campo de trabalho em que esse profissional precisa lançar um olhar mais integrador, dentro da complexidade do real, superando as dicotomias no entendimento da prática cotidiana das pessoas.

Nesse sentido, é fundamental pensar as concepções da Geografia voltadas para o ensino. A prática do ensino de Geografia, desde o início do século XX, é marcada pela memorização, com acento nos dados isolados, o que ocasiona o desinteresse dos alunos, daí a importância de se atribuir significados à Geografia a partir de novos caminhos. Em meados da década de 1980, há uma ampliação de referenciais interpretativos da realidade, surgindo novos e diversos caminhos na investigação geográfica, a chamada Geografia Crítica. Nessa perspectiva, nos anos de 1990, o contexto sociopolítico, científico e educacional apontava para uma crise e crescente ampliação dos referenciais interpretativos da realidade, ocasionando a renovação da Geografia escolar. Esse fato nos remete a falar da presente dicotomia existente entre a Geografia postulada no contexto acadêmico e a Geografia postulada na escola, as quais formam duas estruturas com suas particularidades.

Torna-se importante, assim, o estudo das categorias geográficas que norteiam o ensino de Geografia, a partir das referências acadêmicas e escolares. Neste artigo, em que é dado especial destaque à categoria lugar, cuja finalidade é esclarecer os termos utilizados para tratar dele, ressalta-se que conceito e categoria serão, assim, utilizados: categoria porque o lugar aqui é adotado como categoria de análise e conceito porque não tem como desvincular uma categoria de seu conceito, pois este remete à produção do seu significado construído epistemologicamente na história.

Nesse sentido, parte-se dos pressupostos da globalização e do lugar, enquanto categorias geográficas necessárias à análise da configuração do 
espaço mundial, no que envolve a nova hierarquia dos espaços e a sociedade mundializada. Isso nos remete a uma reflexão sobre uma possível cultura global, em que o local e o lugar têm ressaltadas suas particularidades no mundo globalizado.

Diante desse entendimento, parte-se das contribuições de Lévy (2006, p. 277), que fala em mundialização, afirmando que esta não é um estado, mas sim um processo. A mundialização é um evento com conteúdo geográfico, estudá-la requer que os geógrafos levem em consideração suas temporalidades, muitas vezes, contraditórias, que se entrelaçam. Isso comprova que as distâncias estão sendo reduzidas, em virtude do aumento da velocidade dos deslocamentos, surgindo, então, o que o autor chama de ideia de "encolhimento do planeta". O universo da telecomunicação é um elemento que, sem dúvida, tem revolucionado a relação com a distância e, com isso, as crescentes técnicas de desmaterialização podem ser consideradas como alternativas ao deslocamento ou à copresença. A aposta geral da mundialização pode ser definida com o surgimento de uma sociedade completa, mundialmente, uma "sociedade-mundo", como afirma Lévy (2006, p. 284-285). Porém, é claro que o mundo não é uma sociedade, mas sim um agregado de sociedades que, apesar de compartilhar o ideário de uma "cultura de massa", conhece bem a existência das particularidades de cada lugar.

Nessa perspectiva, torna-se pertinente apresentar as contribuições de Santos (2000), visto que o autor parte do pressuposto de que, em um mundo globalizado, as regiões, as cidades, enfim, certas localidades, tornam-se, através da lógica capitalista de consumo, competitivas. A competitividade torna-se uma regra de convivência e sobrevivência no mercado e na economia mundial, na medida em que ir contra as regras dessa competitividade implica perda de papéis no cenário econômico. Assim, esta categoria vem sendo muito bem aceita e difundida na sociedade contemporânea, “criam-se novos 'valores' em todos os planos, uma nova 'ética' pervasiva e operacional face aos mecanismos da globalização", em que o "consumismo e a competitividade levam ao emagrecimento moral e intelectual da pessoa, à redução da personalidade e da visão do mundo, convidando, também, a esquecer a oposição fundamental entre a figura do consumidor e a figura do cidadão" (p. 57). Nesse sentido, Mattelart (2006, p. 103) afirma que há diferentes sociedades, com suas diferentes particularidades locais que, muitas vezes, reproduzem os signos transna- 
cionais, os adaptam, os reconstroem, os reinterpretam, os reterritorializam. Porém, de qualquer forma, eles estão lá, na sua configuração atual, entre o local e o global. A chamada dimensão global participa também da reconfiguração das identidades, na construção de novos imaginários ou reconfiguração dos antigos que doam seus lugares a "cópias grotescas". Ainda na concepção do autor, estamos assistindo ao ápice dos crescentes processos de concentração e de privatização dos meios para produzir não só opinião, mas também cultura, cultura de massa, uma homogeneização da humanidade, amputada de seus direitos à diversidade.

Debord (1997, p. 14) ressalta o quanto a sociedade atual tem dado valor à imagem, à representação, à aparência, à ilusão; ela se tornou uma sociedade do espetáculo, e "o espetáculo é o âmago do irrealismo da sociedade real”, o espetáculo constitui-se no momento histórico que nos contém. A visão é o sentido mais importante no mundo do espetáculo, e o espetáculo do individual, às vezes, significa mais do que o espetáculo das coisas mais amplas. A verdade é que o mundo real acaba se transformando em simples imagens que acabam tornando-se seres reais. Essa referência é aqui utilizada para ratificar a importância da formação geográfica para a vida dos jovens escolares que, muitas vezes, se veem imersos no que o autor denomina sociedade do espetáculo.

Essa discussão deixa clara a crescente importância que o lugar e sua identidade têm no mundo contemporâneo. Font e Rufi (2006, p. 202) afirmam que deve-se reconhecer, a princípio, que este fenômeno se vê favorecido pela dinâmica geral da economia, da sociedade e da cultura, pois "os diversos processos de globalização hoje existentes desencadearam uma interessante e inesperada tensão dialética entre o global e o local, que está na base do retorno ao lugar”. O fato é que a sensação de impotência, de estar indefeso e de insegurança perante este novo contexto de globalização e internacionalização dos fenômenos humanos provoca um retorno a esferas e escalas menores, um retorno ao lugar. Enfim, a necessidade de se sentir identificado com um espaço específico, local, é novamente sentida pelas pessoas, que precisam se reconhecer e pertencer a algo mais concreto, que possua um significado real.

Ainda segundo esses autores, estamos assistindo a uma revalorização do lugar, e a um renovado interesse por uma nova maneira de interpretar o território de forma que se possa conectar o particular com o geral. Porém, é importante atentarmos que a ação do capital e sua inter- 
nacionalização crescente acabam determinando, de certa forma, a nossa compreensão e experiência do espaço. Claro que isso é insuficiente, posto que ainda existe em todos os grupos sociais a influência da etnia e do gênero, o que nos remete a um exemplo trabalhado por Massey (2000, p. 178), de que as mulheres, muitas vezes, se sentem fora do lugar, não pelo capital, mas pela ação dos próprios homens que compartem com ela determinados locais.

Nesse sentido, se é possível reconhecer que as pessoas possuem identidades múltiplas, o mesmo se pode dizer sobre os lugares, e essas identidades tanto podem ser uma forma de riqueza como podem se converter em conflito. Sendo assim, Massey (2000, p. 183) afirma que as comunidades podem existir sem compartilhar um mesmo lugar, ou seja, não se pode restringir o lugar a um único sentido, seus sentidos são diferentes, tanto que é possível fazer surgir um sentido global do lugar. É nessa perspectiva que a autora defende sua tese da "interpretação alternativa do lugar”: "o que dá a um lugar sua especificidade não é uma história longa e internalizada, mas o fato de que ele se constrói a partir de uma constelação particular de relações sociais” (p. 183). Assim, permite-se um sentido de lugar livre, que inclui uma consciência de suas ligações com o mundo mais amplo, que relaciona de forma lúcida e positiva o local com o global.

O que importa é uma boa medida na hora de fazer a relação entre o local e o global, afinal um está incluído no outro, de forma que ambos devem ter sua importância respeitada em parâmetros locais e globais, dentro de uma sociedade possuidora de características globais e locais. Sendo assim, partilha-se das considerações de Massey (2000, p. 185) no que se refere ao "conceito progressista de lugar", que não pode ser considerado estático, afinal lugares são processos, não possuem fronteiras concretas que os delimite, sendo a ligação com tudo o que é externo uma característica dos lugares. Os lugares não possuem identidades únicas ou singulares, pois são abertos a outras culturas e desprovidos de limites, e o mais importante: nenhuma dessas características nega a importância da singularidade de um lugar, porque sua especificidade é justamente a mistura distinta das relações sociais mais amplas com as mais locais.

Nesse sentido, podemos afirmar que o problema da redefinição do lugar emerge como uma necessidade diante do esmagador processo de globalização. Quanto a isso, Carlos (1996, p. 20) é enfática ao afirmar que “o lugar é a base da reprodução da vida e pode ser analisado pela tríade 
habitante-identidade-lugar. A cidade, por exemplo, produz-se e revela-se no plano da vida e do indivíduo”. Ou seja, o lugar é, na verdade, uma parte do espaço apropriado para o desenvolver da vida, da vida que se reflete através do corpo e dos sentidos, que pode ser realmente sentida em locais como o bairro, as praças, as ruas.

São as relações sociais, políticas, econômicas, culturais que criam o sentido dos lugares, estes são produzidos diariamente por um conjunto de sentidos e valores que são impressos pelo uso (Carlos, 1996). Ainda na concepção da autora, vale ressaltar que um lugar contém sempre o global, é ao mesmo tempo específico e mundial, articula-se a uma rede de lugares, que envolve fluxos de informações, bens e serviços, processos que têm como cenário a mundialização da sociedade e de tudo o que a envolve, constituindo cada vez mais um espaço globalizado articulado, conectado e integrado, o que induz um novo olhar em direção ao local. Assim, o processo de valorização ou de desvalorização dos lugares depende de sua situação como um bom ponto estratégico de investimento ou não, controlado por estruturas globalizantes que permitem ao sistema mundial se manter e se reproduzir.

Carlos (1996, p. 103) traz para a discussão uma questão interessante, que se opõe ao lugar: o não lugar, articulando ideias que envolvem o novo espaço contemporâneo baseado na não identidade e no não reconhecimento. Em virtude das novas relações de espaço e tempo na sociedade mundializada, o espaço se constitui de forma diluída e efêmera, afrouxando os referenciais urbanos que dão sustentação à vida. A autora constrói esse conceito no plano das contradições do espaço, como consequência direta da relação contraditória entre valor e uso.

O lugar e o não lugar dependem em grande escala da relação que os indivíduos mantêm com eles, entendendo-se que a relação entre o homem e o lugar depende da identidade tecida entre ambos. Nesse sentido, concorda-se com Carlos (1996, p. 117), quando esta afirma que a identidade, no plano do vivido, vincula-se ao sentimento de conhecimento e reconhecimento, à natureza humana da identidade, do sentimento de pertencimento. Ela está ligada aos lugares habitados, vividos e sentidos pelos habitantes, aqueles que são marcados pela presença, criados pela história e pelo tempo, gradualmente, no sentido de construção. Isso revela o sentimento de total intimidade daquele que habita um lugar com sua paisagem, o que revela a diferença com o não lugar que, muitas vezes, 
inspira o estranhamento e o não reconhecimento por conta das rápidas modificações no espaço. Assim, o não lugar não é simplesmente uma não aceitação, diferencia-se do lugar pelo seu processo de constituição, que pode ser produto de indústrias turísticas que acabam construindo "simulacros de lugares", através da não identidade.

Um dos efeitos do processo de globalização, apesar de a lógica ser contrária, é ter tornado os sujeitos conscientes de que o mundo pode ser uma localidade, vivida e sentida por seus habitantes. Nesse sentido, Featherstone (1997, p. 131) afirma que o senso de pertencimento, as experiências comuns e as formas culturais que são associadas a um lugar, são fundamentais para o conceito de uma cultura local. No entanto, o conceito de cultura local é relacional, afinal o planeta Terra é uma localidade. Categorias como o local e o global estão em constante relação com o território, a identidade e a cultura, elementos constituintes de sentidos próprios na vida de cada indivíduo que representa a sociedade. Nesse contexto, para levantar questões que envolvem a relação entre a globalização e conceitos como território e identidade, Haesbaert (2007, p. 55) permeia caminhos interessantes. Com a globalização, não só as identidades se envolveram em um movimento mais aberto como o próprio espaço e território, mas estes, em si, passaram a ser construídos de forma múltipla e complexa. Assim, alguns autores reconhecem que o caminho entre território e identidade é constituído por um movimento que vai do território à identidade e da identidade ao território, como categorias indissociáveis, ainda que, às vezes, um prevaleça sobre o outro.

Assim como o lugar, o território representa para os indivíduos uma concepção de mundo, um sentido de pertencimento, pois ele também é um objeto de representações simbólicas. Haesbaert (2007, p. 33) vem tecendo uma discussão que envolve elementos como o território, as identidades territoriais, a multiterritorialidade, o hibridismo cultural e a essencialização das identidades, a fim de ilustrar conflitos de um mundo globalizado. $\mathrm{O}$ autor trabalha com uma abordagem geográfica da identidade, pelo viés das chamadas identidades territoriais. Formula uma discussão que envolve identidade e diferença, afirmando que ocorre uma relação íntima entre elas, partindo do pressuposto de que não há como "se identificar" com algo sem que sua diferenciação seja construída. Enfim, são elementos indissociáveis, o que representa o caráter de alteridade que marca a construção identitária, sempre baseada na relação com o outro. 
Embora a princípio coubesse aos geógrafos restringir sempre o território à dimensão material do espaço enquanto instrumento, na atual lógica global, em que o virtual e a copresença se difundem pelo mundo, ampliando as esferas da imagem e da representação, a dimensão imaterial ou "mais idealista", como afirma Haesbaert (2007, p. 39-40), tem tomado lugar na discussão do território enquanto espaço de representações. Nesse sentido, o autor segue suas discussões orientando-as para a distinção entre território e territorialidade, afirmando que a territorialidade não se restringe a uma dimensão simbólica e cultural do território. Ela vai além, é algo abstrato, a imagem ou o símbolo de um território, uma categoria que efetivamente existe e pode ser "usada de forma eficaz como uma estratégia político-cultural, mesmo que o território ao qual se refira não esteja materialmente manifestado".

É a partir desse entendimento que se pode dizer que a interdependência universal dos lugares é a nova realidade do território e, para o enriquecimento da discussão, torna-se pertinente uma análise das orientações de Santos (1994, p. 15). Segundo o autor, antes, o Estado-Nação moldava o território para servi-lo, hoje nos encontramos em uma noção pós-moderna de transnacionalização do território, em que este é usado como sinônimo de espaço humano habitado. Nessa perspectiva, assiste-se a um novo funcionamento do território, que envolve as horizontalidades e verticalidades propostas pelo autor. Hoje, o que reúne as diferentes porções de um território é a informação, instrumento da união de espaços e pessoas. Esse fato faz emergir um conflito que se agrava entre um espaço local, do vivido e do pertencimento, e um espaço global, da estrutura ideológica de origem distante, que consegue afetar cada lugar, mesmo que de maneira diferente, impondo normas já estabelecidas para que cada localidade possa servi-la. Assim como muitos autores, Santos (1994) acredita que o território se reafirma pelo lugar e não somente pelos novos fundamentalismos do território fragmentado.

Diante do exposto, o estudo do lugar e a sua utilização para ensinar e aprender Geografia se tornam prementes para a formação de cidadãos críticos e conhecedores de seus lurares, capazes de articular sua experiência próxima com elementos globais ou distantes, exercitando assim uma formação cognitiva dialética capaz de ultrapassar os círculos concêntricos empregados na pedagogia tradicional. 


\section{Considerações finais}

A reafirmação do lugar torna-se elemento primordial neste estudo. De acordo com os autores destacados, acredita-se ter, no cenário atual, fortes e marcantes modificações no mundo e na sociedade. Com isso, torna-se pertinente analisar como o professor, a Geografia e a educação podem contribuir com a formação de cidadãos conscientes e críticos, que sejam capazes de transitar entre os conceitos e as abordagens geográficas que representam as transformações contemporâneas. A sociedade urbana, por sua vez, constitui-se em mundialidade, a globalização materializa-se concretamente no lugar, onde se percebe de forma mais real o mundo moderno, com sua fragmentação e tendência à homogeneização, no lugar essas características se tornam reais. O global ganha expressão no e a partir do local, redefinindo seu conteúdo, entendendo que é no lugar que a vida cotidiana ganha existência em suas múltiplas dimensões. Nesse sentido, a categoria lugar vem se constituindo em uma rica ferramenta para o ensino de Geografia. A utilização do lugar para analisar o mundo é eficiente, mas pode ser perigosa e desafiadora dependendo da concepção teórico-metodológica do professor. Straforini (2008, p. 91) ressalta essa preocupação, ao afirmar que

o que se tem verificado na prática pedagógica dos professores é uma total hierarquização do espaço geográfico, onde cada dimensão espacial é ensinada de forma fragmentada e independentemente. Assim, iniciam-se os estudos com os da casa da criança, seguida da rua, da escola, do bairro, da cidade, do estado, da federação, do país, do continente e, por fim, do mundo. Há uma sequência que não pode ser quebrada, e, se tudo der certo, no final do segundo ciclo do Ensino Fundamental ( $4^{\mathrm{a}}$ série), a criança conseguirá compreender a dimensão mundo.

Nos próprios PCN já está posta a preocupação quanto a essa hierarquização do espaço geográfico. Essas orientações contidas nos documentos oficiais postulam que não se deve mais trabalhar do nível local ao mundial hierarquicamente. Ao contrário, deve-se valorizar a compreensão de como a realidade local relaciona-se com o contexto global, e isso deve ser trabalhado de forma abrangente durante toda a escolaridade desde os ciclos iniciais. As diferentes escalas de análises devem ser tratadas para que os alunos compreendam que não são representações do espaço únicas e nem tampouco isoladas. 
Straforini (2008, p. 92), nesse sentido, afirma que "o conceito de realidade ou imediato concreto - o que na Geografia vamos chamar de lugar - utilizado na escola não abrange toda a sua dimensão atual”. O autor destaca que com a globalização e o avanço técnico, científico e informacional, o lugar não pode ser entendido como uma categoria que se encerra em si. Com isso, defende-se a tese de que o lugar atinge uma dimensão de destaque não somente em sua reafirmação na produção teórica geográfica, mas também nas orientações da didática da Geografia, como se tem observado nas pesquisas citadas de Callai (2000) e Straforini (2008), quando estes consideram que o papel do professor é mediar a construção do conhecimento presente no lugar, articulando-o com o todo. Contudo, para isso, a prática pedagógica do professor precisa estar em consonância com o conceito atual de lugar - um motivo importante de se elencar neste artigo algumas referências teóricas atuais para melhor percorrer essa categoria de análise como conceito. Caso o professor não vincule sua prática pedagógica aos elementos teóricos da ciência e ao avanço na produção do conhecimento, o ensino de Geografia continuará fragmentando, o espaço geográfico dividido em fatias descoladas e inertes.

O ponto de partida não deve ser definido, como regra, a partir da realidade mais próxima ou da realidade mais distante, mas da relação que existe entre ambas, e estabelecer esse significado é instrumentalizar a criança e o jovem para compreenderem o mundo. O lugar, na atualidade, deve ser entendido sob uma nova dimensão, para além de sua localização no espaço geográfico, o lugar é a manifestação do encontro de várias escalas, de interesses próximos e distantes - locais e globais (Santos, 1994).

O interesse em trabalhar o lugar como mediação didática no processo de ensino e aprendizagem em Geografia emerge do entendimento de que é possível, a partir do estudo dessa categoria de análise, dimensionar a concretude do mundo no lugar, encontrar os elementos globais no lugar. Estabelecer as relações do próximo com o distante pode levar o jovem a elaborar novas questões sobre o ser e estar no mundo (Straforini, 2008). A categoria lugar possibilita ao professor trazer a realidade dos jovens escolares para as aulas sem se prender aos limites do concreto imediato, embora este tenha papel fundamental na construção do conhecimento histórico e geográfico do espaço vivido. Ao mesmo tempo que é possível trabalhar os interesses próximos, o lugar estabelece oportunidades para a reflexão sobre realidades e ações que estão "fora” do próprio lugar. 
Com isso, destaca-se a importância para o ensino de Geografia, da compreensão da cultura geográfica de jovens estudantes, para a elaboração e sistematização do raciocínio geográfico e o desenvolvimento do pensamento espacial, a partir de uma série de mediações que contribuam com a formação de conceitos, em especial, o estudo do lugar.

\section{Referências}

CALLAI, H. C. Estudar o lugar para compreender o mundo. In: CASTRO GIOVANNI, A. C. (Org.). Ensino de geografia: práticas e textualizações no cotidiano. Porto Alegre: Mediação, 2000.

CARLOS, A. F. A. O lugar no/do mundo. São Paulo: Hucitec, 1996.

CHARLOT, Bernard. Relação com o saber, formação dos professores e globalização: questões para a educação hoje. São Paulo: Artmed, 2005.

DEBORD, G. A sociedade do espetáculo. Tradução de Estela dos Santos Abreu. Rio de Janeiro: Contraponto, 1997.

FEATHERSTONE, M. O desmanche da cultura: globalização, pós-modernismo e identidade. São Paulo: SESC/Studio Nobel, 1997.

FONT, J. N.; RUFI, J. V. (Orgs.). Geopolítica, identidade e globalização. São Paulo: Annablume, 2006.

HAESBAERT, R. Identidades territoriais: entre a multiterritorialidade e a reclusão territorial. In: ARAÚJO, F. G. B.; HAESBAERT, R. (Orgs.). Identidades e territórios: questões e olhares contemporâneos. Rio de Janeiro: Access, 2007.

LÉVY, J. Geografía y mundialización. In: HIERNEAUX, D.; LINDON, A. (Orgs.). Tratado de geografía humana. México: Anthropos; UAM, 2006.

LIBÂNEO, J. C. Docência universitária: formação do pensamento teóricocientífico e atuação nos motivos dos alunos. In: D’ÁVILA, C. (Org.). Ser professor na contemporaneidade: desafios, ludicidade e protagonismo. Curitiba: CRV, 2009.

. Conteúdos, formação de competências cognitivas e ensino com pesquisa: unindo ensino e modos de investigação. In: PIMENTA, S. G.; ALMEIDA, M. I. (Orgs.). Pedagogia universitária: caminhos para a formação de professores. São Paulo: Cortez, 2011.

MASSEY, D. Um sentido global do lugar. In: ARANTES, A. (Org.). O espaço da diferença. São Paulo: Papirus, 2000.

MATTELART, A. História da sociedade da informação. 2. ed. São Paulo: Loyola, 2006.

MOULY, G. J. Psicologia educacional. 5. ed. Tradução de Dante Moreira Leite. São Paulo: Livraria Pioneira, 1973. 
SANTOS, M. O retorno do território. In: SANTOS, M.; SOUZA, M. A.; SILVEIRA, M. (Orgs.). Território, globalização e fragmentação. São Paulo: Hucitec/ANPUR, 1994.

- Por uma outra globalização: do pensamento único à consciência universal. Rio de Janeiro: Record, 2000.

SOUZA, R. C. C. R. de. Universidade, processo de ensino-aprendizagem e inovação. Educação: tendências e desafios de um campo de movimento. In: ENCONTRO DE PESQUISA EM EDUCAÇÃO DA REGIÃO CENTRO-OESTE (ANPED-CentroOeste), 9, 2008, Taguatinga. Anais do IX Encontro de Pesquisa em Educação da Região Centro-Oeste, v. 2. Taguatinga (DF), 2008.

STRAFORINI, R. Ensinar geografia: o desafio da totalidade-mundo nas séries iniciais. São Paulo: Annablume, 2008.

Izabella Peracini Bento - Possui Graduação em Geografia pela Pontifícia Universidade Católica de Goiás. Mestrado e Doutorado em Geografia pela Universidade Federal de Goiás. Atualmente é Professora do Departamento de Geografia da Universidade Federal de Goiás.

Recebido para publicação em 7 de janeiro 2015

Aceito para publicação em $1^{\circ}$ de março de 2015 